\title{
The Effects of Hypoxemia on Myocardial Blood Flow during Exercise
}

\author{
STEPHEN M. PARIDON, J. TIMOTHY BRICKER, WILLIAM J. DREYER, MICHAEL REARDON, \\ E. O'BRIAN SMITH, CO-BURN J. PORTER, LLOYD MICHAEL, AND DAVID J. FISHER \\ Lillie Frank Abercrombie Section of Cardiology, Department of Pediatrics [S.M.P., J.T.B., W.J.D., E.O.S., \\ C.J.P., D.J.F.], Department of Cardiovascular Surgery [M.R.], and Department of Medicine [L.M.], Baylor \\ College of Medicine and Texas Children's Hospital, Houston, Texas 77030
}

\begin{abstract}
We evaluated the adequacy of regional and transmural blood flow during exercise and rapid pacing after 1 wk of hypoxemia. Seven mature mongrel dogs were made hypoxemic (mean $\mathrm{O}_{2}$ saturation $=72.4 \%$ ) by anastomosis of left pulmonary artery to left atrial appendage. Catheters were placed in the left atrium, right atrium, pulmonary artery, and aorta. Atrial and ventricular pacing wires were placed. An aortic flow probe was placed to measure cardiac output. Ten nonshunted dogs, similarly instrumented, served as controls. Recovery time was approximately $1 \mathrm{wk}$. Cardiac output, mean aortic pressure, and oxygen saturation were measured at rest, with ventricular pacing, atrial pacing, and with treadmill exercise. Ventricular and atrial pace and exercise were at a heart rate of 200. Right ventricular free wall, left ventricular free wall, and septal blood flow were measured with radionuclide-labeled microspheres. Cardiac output, left atrial blood pressure, and aortic blood pressure were similar between the two groups of dogs in all testing states. Myocardial blood flow was significantly higher in the right and left ventricular free wall in the hypoxemic animals during resting and exercise testing states. Myocardial oxygen delivery was similar between the two groups of animals. Pacing resulted in an increase in myocardial blood flow in the control animals but not the hypoxemic animals. Myocardial blood flow increased significantly over resting flow with exercise in both groups of animals. Endocardial to epicardial flow ratio were above one and similar both within and between groups of animals for all testing states. We conclude that myocardial blood flow in hypoxemic dogs increases to supply similar oxygen delivery as the control dogs. The endocardial to epicardial ratio would indicate no exhaustion of subendocardial coronary vascular reserve with hypoxemia in any testing state. (Pediatr Res 25:280284, 1989)
\end{abstract}

Children with cyanotic congenital heart disease have a limited exercise capacity. What role the adequacy of myocardial blood flow plays in the exercise limitation of these children is not known. Hypoxemia, polycythemia, and myocardial hypertrophy all have the potential to increase the demands made on myocardial blood flow during exercise. Little is known about their effects on the global and regional myocardial blood flow during exercise.

The purpose of this study was to isolate one of these factors

Received November 18, 1987; accepted November 3, 1988.

Reprints J. Timothy Bricker, Pediatric Cardiology, Texas Children's Hospital, 6621 Fannin, Houston, TX 77030

Supported in part by Grant RR-00188 from General Clinic Research Branch, NIH, and by the American Heart Association, Texas Affiliate Grant G136. by evaluating the effects of hypoxemia on global and regional myocardial blood flow during exercise. In experiments with dogs, we created a left pulmonary artery to left atrial appendage anastomosis that resulted in a level of hypoxemia frequently found in cyanotic congenital heart disease in children. Using isotope-labeled microspheres, we measured transmural and regional blood flow at rest, during atrial and ventricular pacing, and during steady state exercise. We hypothesized that the combined effects of hypoxemia and exercise might result in inadequate myocardial blood flow, especially in vulnerable areas such as the subendocardial region, even in the absence of myocardial hypertrophy and polycythemia. Pacing effects were studied to isolate further the heart rate effects of exercise from the associated increase in catecholamines.

\section{MATERIALS AND METHODS}

Animals used in this study were healthy adult mongrel dogs ranging in wt from 15 to $20 \mathrm{~kg}$. Before surgery, all dogs were familiarized with running on an animal treadmill, using three to four 20-min training sessions. Seven dogs underwent induction of anesthesia with thiopental $25 \mathrm{mg} / \mathrm{kg}$. Anesthesia was maintained with a mixture of halothane and oxygen after intubation and mechanical ventilation. A left lateral thoracotomy was performed through the fifth intercostal space. The left internal thoracic artery was dissected, and a polyvinyl fluid-filled catheter was advanced through the artery into the aortic arch. Similar catheters were placed in the right and left atrial appendages and at the base of the main pulmonary artery $2 \mathrm{~cm}$ distal to the valve annulus. Pacing wires were placed on the right and left atria and the right ventricle. An electromagnetic flow probe was placed around the base of the ascending aorta to measure cardiac output. The left and right pulmonary arteries were then dissected with placement of loose vessel loops of either silk suture or umbilical tape. Noncrushing surgical clamps were placed to occlude the left pulmonary artery totally and the portion of the left atrial appendage adjacent to the left pulmonary artery. An 8-mm anastomosis was created between the left pulmonary artery and the left atrium. The pulmonary bands were then either adjusted or a suture was placed in the anastomosis to reduce the internal diameter of the shunt to result in an arterial $\mathrm{P}_{\mathrm{O}_{2}}$ of $100-150$ torr while the dogs were being mechanically ventilated with $100 \%$ oxygen. At no time was the systolic pulmonary artery pressure proximal to the shunt allowed to exceed $50 \%$ of the systemic systolic pressure. The thoracotomy was closed, and the catheters, flow probe, and pacing wires were tunneled to the midback. The dogs were weaned from mechanical ventilation. Ten dogs instrumented similarly but without a shunt served as controls. The dogs were allowed to recover and received daily antibiotics. Intramuscular meperidine, $0.5-1.0 \mathrm{mg} / \mathrm{kg}$ was given in the first 1 to $3 \mathrm{~h}$ postoperatively for signs of pain or respiratory distress. 
The chest tubes were removed on approximately the 3rd postoperative day. Studies were performed $1 \mathrm{wk}$ after surgery.

Experimental protocol. On the d of the study, the dogs were brought to the laboratory and placed in a sling that restrained them in the normal standing position. While the dogs were resting quietly, mean and phasic right atrial, left atrial, pulmonary artery, and aortic pressures were recorded from the fluid-filled catheters using Statham P23Db pressure transducers and an eight-channel high fidelity Gould recorder. Pressure gauges were placed at the lower fourth of the dog's chest just posterior to the front legs. Systemic cardiac output was measured with an electromagnetic flow probe. Systemic arterial and right atrial blood gases, oxygen saturation, and $\mathrm{Hb}$ were obtained. Then, $1.5-2.0 \times 10^{6}$ radionuclide-labeled microspheres of $15-\mu$ diameter were injected into the left atrium while blood samples were continuously withdrawn from the aorta at a rate of $4 \mathrm{ml} / \mathrm{min}$ for a period of $1.5 \mathrm{~min}$. Isotopes used included ${ }^{85} \mathrm{Sr},{ }^{46} \mathrm{Sc},{ }^{95} \mathrm{Nb}$, and ${ }^{141} \mathrm{Cs}$.

After this procedure, the ventricle was then paced at a rate of 200 beats/min for $10 \mathrm{~min}$. At the end of this time, all the above measurements were repeated, then a second injection of microspheres was given. The dog was then allowed to return to baseline state over approximately $10 \mathrm{~min}$ as judged by heart rate, systemic pressure, and cardiac output.

Next, left atrial pacing with one to one ventricular conduction at a rate of 200 beats/min was performed for $10 \mathrm{~min}$. The same measurements were repeated, and a third injection of microspheres was given.

After again returning to baseline state, the dog was then placed on a treadmill. The dog was then exercised at the work load necessary to achieve a heart rate of 200 beats/min. The work consisted of a $20 \%$ grade with a speed varying from 1 to $4 \mathrm{mph}$ depending upon the speed required to obtain a steady state heart rate of 200 beats/min. Hypoxemic dogs required a lower work load to achieve the same steady state heart rate than control dogs. After the dogs exercised for $10 \mathrm{~min}$ at this work load, all measurements were repeated, and a fourth injection of microspheres was given.

Immediately after the study protocols, all dogs were killed. The heart was removed, weighed, and placed in $10 \%$ formaldehyde solution. It was sectioned into left ventricular free wall, septum, and right ventricular free wall. The right and left free walls were divided into epicardial, midmyocardial, and endocardial sections of approximately equal thickness. The septum was divided into left, right, and midmyocardial sections of approximately equal thickness. These specimens were then weighed and placed in counter vials. Sections of the right and left cerebral hemispheres were removed, weighed, and placed in counter vials preserved with formalin.

Calculated data. Myocardial blood flow for each of the testing states in $\mathrm{ml} / \mathrm{min} / 100 \mathrm{~g}$ of tissue was calculated for each of the tissue samples using standard techniques. The endocardial to epicardial flow ratio for the right and left ventricular free walls was determined from measurement of the blood flow in $\mathrm{ml} /$ $\mathrm{min} / 100 \mathrm{~g}$ of tissue from the subendocardial tissue samples divided by the flow to the subepicardial sample. Cardiac output was indexed to body wt by dividing the cardiac output by the wt of the dog in $\mathrm{kg}$. Systemic vascular resistance was calculated for each of the four testing states. This was the quotient of the difference between the mean aortic blood pressure and the mean right atrial pressure divided by the cardiac index.

Statistical analysis. All data were analyzed using ANOVA for repeat measurements. The Bonferroni adjustment was used so that value of $p<0.02$ was considered to be statistically significant.

\section{RESULTS}

Table 1 summarizes hemodynamic data for all testing states. Cardiac index was similar for control and hypoxemic dogs for each testing state. Pacing did not cause a significant change in cardiac index. Exercise caused an increase in cardiac output over the resting state in both groups of dogs. Systemic vascular resistance was similar between the control and hypoxemic dogs in all testing states. Pacing was not associated with a change in systemic vascular resistance with exercise. The left atrial pressure tended to be lower in the hypoxemic dogs, but was significantly different only in the exercise state. Aortic blood pressure tended to be lower in the hypoxemic dogs in all testing states except exercise. The pulmonary blood pressure measured in the proximal main pulmonary artery was similar in both groups except for a significant increase in the hypoxemic group during exercise.

$\mathrm{Hb}$ concentration in $\mathrm{g} / 100 \mathrm{ml}$ for the control and cyanotic dogs was similar at 12.0 and 13.0 , respectively. Oxygen saturation data are summarized in Table 2. A significant level of arterial hypoxemia was achieved with the shunted dogs. A further drop in oxygen saturation was observed with exercise but not with pacing. The difference between the arterial and venous oxygen saturation was higher with exercise than the resting or paced states in the control and the hypoxemic animals. Systemic oxygen consumption increased with exercise in both groups. Although the exercise oxygen consumption increase in the control group was higher than in the hypoxemic group, the difference was not statistically significant. This may be a reflection of the lesser

Table 1. Hemodynamic data testing states*

\begin{tabular}{|c|c|c|c|c|c|}
\hline & & Resting & $\begin{array}{l}\text { Ventricular } \\
\text { pacing }\end{array}$ & $\begin{array}{l}\text { Atrial } \\
\text { pacing }\end{array}$ & Exercise \\
\hline Cardiac index $(\mathrm{ml} / \mathrm{min} / \mathrm{kg})$ & $\begin{array}{l}\text { Control } \\
\text { Cyanotic }\end{array}$ & $\begin{array}{r}107 \pm 60 \\
93 \pm 20\end{array}$ & $\begin{array}{l}99 \pm 66 \\
88 \pm 26\end{array}$ & $\begin{array}{r}100 \pm 66 \\
90 \pm 21\end{array}$ & $\begin{array}{l}189 \pm 75 \dagger \\
159 \pm 58 \dagger\end{array}$ \\
\hline $\begin{array}{l}\text { Systemic vascular resistance } \\
\qquad \frac{\mathrm{mm} \mathrm{Hg}}{\mathrm{ml} / \mathrm{min} / \mathrm{kg}}\end{array}$ & $\begin{array}{l}\text { Control } \\
\text { Cyanotic }\end{array}$ & $\begin{array}{l}1.12 \pm 0.15 \\
1.04 \pm 0.20\end{array}$ & $\begin{array}{l}1.17 \pm 0.38 \\
1.19 \pm 0.28\end{array}$ & $\begin{array}{l}1.25 \pm 0.07 \\
0.98 \pm 0.09\end{array}$ & $\begin{array}{l}0.64 \pm 0.20 \dagger \\
0.68 \pm 0.13 \dagger\end{array}$ \\
\hline Left atrial mean pressure (mm Hg) & $\begin{array}{l}\text { Control } \\
\text { Cyanotic }\end{array}$ & $\begin{array}{l}7.4 \pm 2.1 \\
5.9 \pm 3.2\end{array}$ & $\begin{array}{l}9.9 \pm 2.0 \\
6.5 \pm 1.8\end{array}$ & $\begin{array}{l}7.9 \pm 1.8 \\
5.8 \pm 2.9\end{array}$ & $\begin{array}{l}8.1 \pm 4.3 \\
2.8 \pm 2.8 \ddagger\end{array}$ \\
\hline $\begin{array}{l}\text { Aortic mean blood pressure (mm } \\
\quad \mathrm{Hg})\end{array}$ & $\begin{array}{l}\text { Control } \\
\text { Cyanotic }\end{array}$ & $\begin{array}{l}111 \pm 10 \\
96 \pm 15 \ddagger\end{array}$ & $\begin{aligned} 111 & \pm 11 \\
99 & \pm 13 \div\end{aligned}$ & $\begin{aligned} 112 & \pm 10 \\
96 & \pm 13 \div\end{aligned}$ & $\begin{array}{l}120 \pm 11 \\
111 \pm 18 \dagger\end{array}$ \\
\hline $\begin{array}{l}\text { Pulmonary artery mean blood pres- } \\
\text { sure }\end{array}$ & $\begin{array}{l}\text { Control } \\
\text { Cyanotic }\end{array}$ & $\begin{array}{l}21 \pm 3 \\
22 \pm 5\end{array}$ & $\begin{array}{l}22 \pm 6 \\
23 \pm 6\end{array}$ & $\begin{array}{l}24 \pm 7 \\
20 \pm 3\end{array}$ & $\begin{array}{l}23 \pm 6 \\
35 \pm 13+t\end{array}$ \\
\hline
\end{tabular}

$*$ All values are expressed as means $\pm 1 \mathrm{SD}$.

$\dagger$ Different from resting values at $p<0.02$.

$\mp$ Cyanotic different from control value at $p<0.02$. 
Table 2. Oxygen saturation data testing states*

\begin{tabular}{|c|c|c|c|c|c|}
\hline & & Resting & $\begin{array}{l}\text { Ventricular } \\
\text { pacing }\end{array}$ & $\begin{array}{l}\text { Atrial } \\
\text { pacing }\end{array}$ & Exercise \\
\hline $\mathrm{Pa}_{\mathrm{O}_{2}}(\mathrm{~mm} \mathrm{Hg})$ & $\begin{array}{l}\text { Control } \\
\text { Cyanotic }\end{array}$ & $\begin{array}{l}87.3 \pm 8.4 \\
39.8 \pm 7.9 \dagger\end{array}$ & $\begin{array}{l}87.1 \pm 9.0 \\
39.3 \pm 7.2 \dagger\end{array}$ & $\begin{array}{l}86.9 \pm 9.1 \\
41.8 \pm 7.9 \dagger\end{array}$ & $\begin{array}{l}85.4 \pm 7.5 \\
32.9 \pm 6.7 \dagger\end{array}$ \\
\hline$\% \mathrm{O}_{2}$ arterial saturation & $\begin{array}{l}\text { Control } \\
\text { Cyanotic }\end{array}$ & $\begin{array}{l}99.4 \pm 0.9 \\
72.4 \pm 8.6 \dagger\end{array}$ & $\begin{array}{l}99.4 \pm 2.0 \\
72.5 \pm 8.0 \dagger\end{array}$ & $\begin{array}{l}98.7 \pm 1.2 \\
74.8 \pm 7.3 \dagger\end{array}$ & $\begin{array}{l}98.4 \pm 1.5 \\
65.7 \pm 9.4+\neq\end{array}$ \\
\hline $\begin{array}{l}\text { Arteriovenous } \% \mathrm{O}_{2} \text { saturation } \\
\text { difference }\end{array}$ & $\begin{array}{l}\text { Control } \\
\text { Cyanotic }\end{array}$ & $\begin{array}{l}31.5 \pm 3.4 \\
32.0 \pm 5.6\end{array}$ & $\begin{array}{l}36.1 \pm 5.7 \\
29.5 \pm 4.2\end{array}$ & $\begin{array}{l}36.1 \pm 5.5 \\
30.9 \pm 6.4\end{array}$ & $\begin{array}{l}58.8 \pm 8.9 \ddagger \\
38.2 \pm 6.0 \ddagger\end{array}$ \\
\hline $\begin{array}{l}\text { Systemic } \mathrm{O}_{2} \text { consumption }(\mathrm{ml} / \\
\mathrm{min} / \mathrm{kg} \text { ) }\end{array}$ & $\begin{array}{l}\text { Control } \\
\text { Cyanotic }\end{array}$ & $\begin{array}{l}4.84 \pm 1.2 \\
4.81 \pm 2.3\end{array}$ & $\begin{array}{l}5.58 \pm 2.0 \\
4.04 \pm 2.0\end{array}$ & $\begin{array}{l}5.10 \pm 2.6 \\
4.00 \pm 2.1\end{array}$ & $\begin{array}{r}14.86 \dagger \pm 3.9 \\
9.96 \dagger \pm 5.3\end{array}$ \\
\hline
\end{tabular}

$*$ All values are expressed as means $\pm 1 \mathrm{SD}$.

$\uparrow$ Cyanotic different from control value at $p<0.02$.

$\uparrow$ Different from resting values at $p<0.02$.

Table 3. Transmural myocardial blood flow testing states*

\begin{tabular}{|c|c|c|c|c|c|}
\hline & & Resting & $\begin{array}{l}\text { Ventricular } \\
\text { pacing }\end{array}$ & $\begin{array}{l}\text { Atrial } \\
\text { pacing }\end{array}$ & Exercise \\
\hline Left ventricle $(\mathrm{ml} / \mathrm{min} / 100 \mathrm{~g})$ & $\begin{array}{l}\text { Control } \\
\text { Cyanotic }\end{array}$ & $\begin{array}{l}112.7 \pm 43 \\
166.3 \pm 65\end{array}$ & $\begin{array}{l}173.5 \pm 42 \\
184.8 \pm 41\end{array}$ & $\begin{array}{l}190.2 \pm 55 \dagger \\
133.1 \pm 41 \dagger\end{array}$ & $\begin{array}{l}217.4 \pm 99 \dagger \\
283.4 \pm 125+t\end{array}$ \\
\hline Right ventricle $(\mathrm{ml} / \mathrm{min} / 100 \mathrm{~g})$ & $\begin{array}{l}\text { Control } \\
\text { Cyanotic }\end{array}$ & $\begin{array}{c}88.9 \pm 49 \\
149.1 \pm 76 \neq\end{array}$ & $\begin{array}{r}96.8 \pm 27 \\
114.5 \pm 18\end{array}$ & $\begin{array}{l}130.2 \pm 60 \\
107.7 \pm 28\end{array}$ & $\begin{array}{l}183.1 \pm 129 \dagger \\
306.9 \pm 165 \dagger t\end{array}$ \\
\hline $\begin{array}{l}\text { Intraventricular septum (ml/ } \\
\min / 100 \mathrm{~g})\end{array}$ & $\begin{array}{l}\text { Control } \\
\text { Cyanotic }\end{array}$ & $\begin{array}{l}136.6 \pm 51 \\
152.7 \pm 74\end{array}$ & $\begin{array}{l}146.4 \pm 63 \\
134.0 \pm 43\end{array}$ & $\begin{array}{l}213.2 \pm 57 \\
129.9 \pm 35 \neq\end{array}$ & $\begin{array}{l}239.6 \pm 96 \dagger \\
272.1 \pm 123 \dagger\end{array}$ \\
\hline
\end{tabular}

${ }^{*}$ All values are expressed as means $\pm 1 \mathrm{SD}$.

$\dagger$ Different from resting values at $p<0.02$.

$\ddagger$ Cyanotic different from control value at $p<0.02$.

Table 4. Left ventricular myocardial oxygen delivery*

\begin{tabular}{|c|c|c|c|c|c|}
\hline & & Resting & $\begin{array}{l}\text { Ventricular } \\
\text { pacing }\end{array}$ & $\begin{array}{l}\text { Atrial } \\
\text { pacing }\end{array}$ & Exercise \\
\hline $\mathrm{O}_{2}$ delivery $(\mathrm{ml} / \mathrm{min} / \mathrm{kg})$ & $\begin{array}{l}\text { Control } \\
\text { Cyanotic }\end{array}$ & $\begin{array}{l}17.0 \pm 4.1 \\
210 \pm 6.9\end{array}$ & $\begin{array}{l}27.6 \pm 9.4 \dagger \\
23.6 \pm 4.8\end{array}$ & $\begin{array}{l}28.8 \pm 6.5 \dagger \\
17.5 \pm 3.4 t\end{array}$ & $\begin{array}{l}30.1 \pm 8.1 \dagger \\
315 \pm 125 t\end{array}$ \\
\hline
\end{tabular}

* All values are expressed as means $\pm 1 \mathrm{SD}$.

$\uparrow$ Different from resting values at $p<0.02$.

$\ddagger$ Cyanotic different from control value at $p<0.02$.

work load required to achieve the heart rate of 200 beats $/ \mathrm{min}$ in the hypoxemic group compared to the control group. The arterial $\mathrm{pH}$ during the testing states for both groups remained above 7.40 .

Transmural myocardial blood flow in $\mathrm{ml} / \mathrm{min} / 100 \mathrm{~g}$ of tissue is summarized in Table 3 for the left and right ventricular free walls and the ventricular septum. In the control groups, the left ventricular free wall blood flow increased approximately $55-65 \%$ with ventricular and atrial pacing. This difference was significant, however, only for atrial pacing. There was a further increase in myocardial blood flow with exercise. The hypoxemic group showed no significant change in myocardial blood flow with pacing. In fact, the lowest myocardial blood flow found was with atrial pacing. Left ventricular myocardial blood flow with exercise was increased over the resting value for the hypoxemic group. Comparison of myocardial blood flow between the hypoxemic and control animals showed that, at both rest and exercise, myocardial blood flow was higher in the hypoxemic animals than in the control animals.

Right ventricular free wall and septum showed similar myocardial blood flow patterns (increased flow with exercise compared to rest for both groups of animals). There was no significant change over resting values with pacing. Right ventricular free wall blood flow was greater in the hypoxemic animals at rest and with exercise than the right ventricular free wall blood flow in control animals.

Left ventricular free wall oxygen delivery was similar for both groups in each of the experimental states except for the atrial pacing, which showed lower oxygen delivery in the hypoxemic animals than for the control animals (Table 4). With pacing, oxygen delivery in the control animals increased compared to the resting state. By contrast there was no increase in the hypoxemic animals with pacing. Both hypoxemic and control animals did show an increase in oxygen delivery compared to the resting state during exercise.

Table 5 shows the ratios of blood flow for the subendocardial and subepicardial myocardium of the left and right ventricular free walls. Although there is a small decrease in the flow ratios with exercise, as has been seen in previous studies, all values are well above unity. There is no significant difference between the control and hypoxemic dogs.

\section{DISCUSSION}

Myocardial blood flow reserve is traditionally defined as the difference between the flow measured in a given testing state and 
Table 5. Endocardial to epicardial flow ratios testing states*

\begin{tabular}{|c|c|c|c|c|c|}
\hline & & Resting & $\begin{array}{c}\text { Ventricular } \\
\text { pacing }\end{array}$ & $\begin{array}{l}\text { Atrial } \\
\text { pacing }\end{array}$ & Exercise \\
\hline \multirow[t]{2}{*}{ Left ventricle } & Control & $1.39 \pm 0.30$ & $1.33 \pm 0.31$ & $1.29 \pm 0.14$ & $1.24 \pm 0.13$ \\
\hline & Cyanotic & $1.26 \pm 0.17$ & $1.43 \pm 0.36$ & $1.33 \pm 0.17$ & $1.17 \pm 0.15$ \\
\hline \multirow[t]{2}{*}{ Right ventricle } & Control & $1.42 \pm 0.60$ & $1.21 \pm 0.21$ & $1.18 \pm 0.16$ & $1.18 \pm 0.19$ \\
\hline & Cyanotic & $1.07 \pm 0.21$ & $1.13 \pm 0.41$ & $1.15 \pm 0.30$ & $1.03 \pm 0.24$ \\
\hline
\end{tabular}

* All values are expressed as means $\pm 1 \mathrm{SD}$.

the flow measured under similar conditions after maximum coronary vasodilatation. Myocardial blood flow reserve in cyanotic congenital heart disease is potentially reduced by several physiologic and hemodynamic perturbations. The presence of hypoxemia will reduce the oxygen-carrying capacity of the blood that perfuses the myocardium. In addition, the presence of myocardial hypertrophy and changes in $\mathrm{Hb}$ concentration will also affect reserve (1-3). With exercise, any or all of these factors listed could potentially result in exhaustion of myocardial blood flow reserve and subsequent myocardial ischemia. In this study, we do not evaluate myocardial blood flow reserve in the classic sense because we did not measure coronary blood flow in each of the testing states before and after maximum coronary vasodilatation. Rather, we assessed the adequacy of the myocardial blood flow to meet the metabolic demand of the myocardium in each of the testing states. Because we measured regional as well as transmural blood flow, we can comment on flow reserve to the subendocardium. Maximum coronary vasodilatation of the subendocardial blood vessels and resultant loss of autoregulating capacity cause reversal of the endocardial to epicardial flow ratios. This ratio can, therefore, be used to assess whether subendocardial blood flow reserve has been exhausted.

In this study, we isolated the effects of hypoxemia on global and regional myocardial blood flow during steady state exercise. We believe this model is an improvement on previous studies of hypoxemia in that it is not an acute preparation and avoids additional compounding variables that might effect myocardial blood flow and reserve. It is not as "chronic" as patients with congenital heart defects, but if it were, our model would be confounded by increased hematocrit and hypertrophy, as well as metabolic changes that affect unloading of oxygen at the tissue level, such as changes in the oxygen dissociation curve.

Early models of hypoxemia generally consisted of acute anesthetized preparations or conscious animals breathing air with acutely reduced $\mathrm{Fi}_{\mathrm{O}_{2}}$. Thus the effects of autonomic and circulating catecholamines caused by acute stress were not well controlled (4-9). In addition, the anesthetics themselves alter global and regional myocardial blood flow (10).

More recent studies have used more chronic models of hypoxemia with various types of surgically created shunts $(11-12)$. Unlike our preparations, these models relied on the development of right ventricular hypertrophy to generate right to left shunting. This model does not allow the differentiation between the effects of hypertrophy and hypoxemia on myocardial blood flow.

In addition, the chronicity of these models results in the expected increase in hemoglobin content seen in long-term hypoxemia. The effects of $\mathrm{Hb}$ concentration on the myocardial blood flow are complex. The oxygen-carrying capacity increases with increasing hemoglobin concentration. At the same time, viscosity becomes an important factor in limiting myocardial blood flow when hemoglobin concentration rises significantly out of the normal physiologic range (13-14).

The model used in this study controls for the factors just discussed. There was no pressure overload on the right ventricle except for the very brief period of time the animal was actually exercising during the testing procedure. The right-sided pressures during the resting state for the hypoxemic dogs were similar to the control values. The model was of sufficiently short duration that polycythemia was not induced as $\mathrm{Hb}$ concentrations were similar for both the hypoxemic and control dogs. Therefore, we feel that our model is well suited to evaluate the isolated effects of hypoxemia on myocardial blood flow both at rest and with the superimposed stress of exercise.

Myocardial blood flow patterns observed in the resting state confirm findings of both previous acute and chronic preparation $(4-9,11,12)$. That is, myocardial blood flow in $\mathrm{ml} / 100 \mathrm{~g}$ of tissue is significantly greater with hypoxemia that results in a hemoglobin desaturation below approximately $80 \%$. Examination of oxygen delivery to the myocardium shows that it remains similar to control values. Thus, the increase in myocardial blood flow is only of sufficient degree to compensate for the decrease in oxygen-carrying capacity caused by the hypoxemia. The endocardial to epicardial flow ratio for the left ventricle at rest was well above one. Therefore, autoregulation was still intact under this condition and subendocardial flow reserve had not been exhausted.

We felt that the additional metabolic demands made on the myocardium during exercise superimposed on hypoxemia might result in inadequate myocardial blood flow. With exercise, there is an increase in heart rate, blood pressure, cardiac output, and sympathetic tone. All of these factors result in an increase in myocardial oxygen demand $(3,15)$. In our pacing and exercise protocols, we examined the changes in the effect on myocardial blood flow, independent of these factors.

Pacing resulted in a 50-60\% increase in myocardial blood flow over the resting state in the control animals. This is similar to previous studies (16-19). The hypoxemic animals, by contrast, had a tendency not to change, or they decreased flow during the pacing protocols. Cardiac output and heart rate were similar between the control and hypoxemic groups, but aortic blood pressure tended to be lower in the hypoxemic group during pacing. This did not significantly decrease systemic vascular resistance but may have resulted in less of a myocardial oxygen demand in the hypoxemic group. We are unable to explain the difference in the response to pacing between the two groups, but it is interesting that the drop in systemic blood pressure in the hypoxemic group allowed them to maintain the same cardiac output and heart rate with a lower myocardial blood flow and presumably a lower myocardial oxygen consumption.

Examination of the regional blood flow during pacing shows all endocardial to epicardial flow ratios to be well above one. This would indicate endocardial flow reserve was not exhausted and autoregulation remains intact.

During exercise, increased sympathetic tone results in stimulation of sympathetic receptors in the coronary vessels. $\beta$-tone appears to be near maximal at rest, and with increased stimulation the effects on the coronary vessels appear to be primarily $\alpha$ constrictor in nature (20-23). Although this $\alpha$-tone is overridden to a great extent by metabolic vasodilatation, sympathetic $\alpha$ constriction may decrease myocardial blood flow by as much as $30 \%$ with exercise $(21-23)$.

Recent work has suggested that $\alpha$-tone during exercise may have a beneficial effect on the transmural distribution of myocardial blood flow. $\alpha$-receptors appear to be more abundant in the epicardial vessels, resulting in a relatively higher vascular resistance in these vessels with exercise. The net effect appears to be preservation of blood flow to the subendocardial region during a period of high oxygen demand by these tissues (24). 
In each of the animals studied, we individualized the work load to achieve a target heart rate of 200 beats $/ \mathrm{min}$. We felt this was an appropriate target heart rate as it is approximately $80 \%$ of the predicted maximum heart rate for dogs. This is a frequently used target level for cardiovascular conditioning programs, so it would reflect a work level that might frequently be encountered in a clinical setting.

The work load needed to achieve the target heart rate was usually much less in the hypoxemic group compared to the controls. Despite this discrepancy in work load, myocardial oxygen demands were probably very similar in both groups of animals. The cardiac output was similar. The product of systemic blood pressure and heart rate have been shown to correlate well with myocardial oxygen consumption, and this product was similar between the groups (25-27).

Transmural myocardial blood flow during exercise increased significantly in both the control and the hypoxemic animals. As with the resting state, the increase in blood flow to the myocardium in the hypoxemic group, although significantly greater than the control group, was sufficient only to result in similar oxygen delivery to both groups.

There was no significant difference in the endocardial to epicardial flow ratios for the control and the hypoxemic animals. All values were well above unity, suggesting that subendocardial flow reserve had not been exhausted. There was a decrease in the endocardial to epicardial flow ratio from the control to the exercise state in both groups, but it was not statistically significant. This is consistent with normal response to exercise seen in previous investigations (15).

These results are consistent with what has previously been shown about coronary vascular reserve (3). In a nonhypoxemic state, coronary vascular reserve is large because of the myocardium's ability to increase its resting blood flow 4- to 5-fold with increasing demand (15). Although the hypoxemia induced in this study results in an expected increase in resting myocardial blood flow, it would appear that the coronary vascular reserve remains adequate, even under these circumstances, to avoid regional underperfusion during exercise.

In summary, the model used in this study resulted in a marked systemic hypoxemia of moderate duration without significant polycythemia or myocardial hypertrophy. At this level of hypoxemia, myocardial blood flow appears adequate to meet myocardial metabolic demands both at rest and with tachycardia induced by the pacing protocols. At the level of exercise used in this study, myocardial blood flow was adequate to meet the metabolic demands of the myocardium, and endocardial to epicardial flow ratios were normal, indicating autoregulation in the subendocardium remained intact and subendocardial blood flow reserve was not exhausted.

\section{REFERENCES}

1. Hoffman JIE, Buckberg GD 1978 The myocardial supply:demand ratio - a critical review. Am J Cardiol 41:327-332

2. Brazier J, Cooper N, Buckberg $G 1974$ The adequacy of subendocardial oxygen delivery. Circulation 49:968-977

3. Hoffman JIE 1984 Maximal coronary flow and the concept of coronary vascular reserve. Circulation 70:153-159

4. Fisher DJ 1984 Increased regional myocardial blood flows and oxygen deliveries during hypoxemia in lambs. Pediatr Res 18:602-606

5. Nakamura Y, Takahashi M, Takei F, Matsumura N, Scholkens B, Sasmoto H 1969 The change in coronary vascular resistance during acute induced hypoxia - with special reference to coronary vascular reserve. Cardiologia 54:91-103

6. Vance JP, Parratt JR, Ledingham I 1971 The effects of hypoxia on myocardial blood flow and oxygen consumption: negative role of beta adrenoreceptors. Clin Sci 41:257-273

7. Berne RM, Blackmon JR, Gardner TH 1957 Hypoxemia and coronary blood flow. J Clin Invest 36:1101-1106

8. Folle LE, Aviado DM 1965 Cardiovascular effects of anoxia and the influence of a new beta adrenergic receptor blocking drug. J Pharm Exp Therap 149:79-90

9. Erickson HH, Stone HL 1972 Cardiac beta-adrenergic receptors and coronary hemodynamics in the conscious dog during hypoxic hypoxia. Aerospace Med 43:422-428

10. Vatner SF, Smith NT 1974 Effects of halothane on left ventricular function and distribution of regional blood flow in dogs and primates. Circulation Res 34:155-167

11. Teitel D, Sidi D, Bernstein D, Heymann MA, Rudolph AM 1985 Chronic hypoxemia in the newborn lamb: cardiovascular, hematopoietic, and growth adaptations. Pediatr Res 19:1004-1010

12. Bernstein D, Teitel D, Sidi D, Heymann MA, Rudolph AM 1987 Redistribution of regional blood flow and oxygen delivery in experimental cyanotic heart disease in newborn lambs. Pediatr Res 22:389-393

13. Surjadjana A, Rouleau J, Boerboom L, Hoffman JIE 1978 Myocardial blood flow and its distribution in anesthetized polycythemic dogs. Circ Res 43:619631

14. Baer RW, Vlahakes GJ, Uhlig PN, Hoffman JIE 1987 Maximum myocardial oxygen transport during anemia and polycythemia in dogs. Am J Physiol 252:H1086-H1095

15. Feigl EO 1983 Coronary physiology. Physiol Rev 63:1-205

16. Gibbs CL 1978 Cardiac energetics. Physiol Rev 58:174-239

17. Allison TB, Holsinger JW 1977 Transmural metabolic gradients in the normal dog left ventricle: effect of right atrial pacing. Am J Physiol 233:H217-H221

18. Weiss HR 1979 Regional oxygen consumption and supply in the dog heart effect of atrial pacing. Am J Physiol 236: $\mathrm{H} 231-\mathrm{H} 237$

19. Bache RJ, Alexander JA, Rembert JC, Greenfield JC Jr 1970 Coronary hemodynamic responses to paired ventricular stimulation in the awake dog. J Appl Physiol 28:145-150

20. Mudge GH Jr, Goldberg S, Gunther S, Mann T, Grossman W 1979 Comparison of metabolic and vasoconstrictor stimuli on coronary vascular resistance in man. Circulation 59:544-550

21. Ekstrom-Jodal B, Haggendal E, Malmberg R, Svedmyr N 1972 The effect of adrenergic beta receptor blockade on coronary circulation in man during work. Acta Med Scand 191:245-248

22. Murray PA, Vatner SF 1979 Alpha adrenoceptor attenuation of the coronary vascular response to severe exercise in the conscious dog. Circ Res 45:654660

23. Mohrman DE, Feigl EO 1978 Competition between sympathetic vasoconstriction and metabolic vasodilation in the canine coronary circulation. Circ Res 42:79-86

24. Huang AH, Feigl EO 1988 Adrenergic coronary vasoconstriction helps maintain uniform transmural blood flow distribution during exercise. Circ Res 62:286-298

25. Baller D, Bretschneider HJ, Hellige G 1981 A critical look at currently used indirect indices of myocardial oxygen consumption. Basic Res Cardiol 76:163-181

26. Kitamura K, Jorgensen CR, Gobel FL, Taylor HL, Wang Y 1972 Hemodynamic correlates of myocardial oxygen consumption during upright exercise. J Appl Physiol 32:516-522

27. Parmley WW, Tyberg JV 1977 Determinants of myocardial oxygen demand. Prog Cardiol 5:19-26 